\title{
THE USE OF HORMONES IN OBSTETRICS AND GYNECOLOGY.
}

\author{
By JOHN BEATTIE, M.D., F.R.C.S., M.C.O.G. \\ (Assistant Physician Accoucheur, St. Bartholomew's Hospital.)
}

The ovary and anterior lobe of the pituitary are capable of supplying endocrine substances of great therapeutic value, and the useful application of these substances is becoming more and more extensive. It is important, however, to realize that endocrine administration is, almost exclusively, a substitution therapy and there is little evidence that hormones administered by mouth, or by injection, act as a stimulant to the gland from which they are derived.

It is possible for large doses of one hormone to affect the production of hormones from another gland. The administration of an anterior lobe hormone can stimulate ovarian activity, but such administration will almost certainly fail to produce a permanent increased activation of the anterior lobe of the pituitary gland in the patient thus treated. There is a little experimental evidence for assuming that one gland may be ultimately stimulated to increased activity by first inhibiting its secretion by injecting a hormone of another type, so that when the injections cease, the original gland may begin to secrete again in a more activee manner. This theory is, at present, not proved sufficiently to allow of its appli-⿳亠丷厂二 cation in clinical medicine, so that the use of hormones must be confined to substitution therapy alone. The promiscuous use of endocrine substances is certainly valueless, and is sometimes harmful.

It is essential to understand the physiology of the reproductive cycle before hormone therapy can be used with intelligence. When this is understood, the part played by certain pathological conditions arising in this system, can be treated, on rational lines, by hormone therapy. There is little doubt that more interest should be taken in the various abnormalities which arise in the menstrual and reproductive cycles in women, for recent research makes this justifiable, and the hope of cure by hormone therapy becomes more likely as time goes on.

Hormone therapy is made most complex to the clinician by the nomenclature used to describe doses of endocrine substances. The position is now clarified considerably by the description of doses in milligrammes weight. This applies to ostrin and corpus luteum hormones, and when using these substances, it is recommended that they should be considered in terms of weight, as well as in terms of units of dosage.

The use of hormones should be confined solely to preparations of known composition, and made by reputable firms who state the exact contents and dose of the substance on the preparations supplied. The day is long past when it was customary to prescribe a mixture of gland extracts in order to obtain therapeutic effects. It is now quite unjustifiable to use hormones promiscuously, and it is essential to use preparations of known potency and dose. 
CEstrogenic hormone, folliculin, cestrin is produced by the ovary and found in huge quantity also in the placenta. The first œstrogenic substance to be isolated in the pure state was œestrone (keto hydroxy œstrin), of which the maximum solubility in oil is only about I.o mg/c.c. (I0,000 International units). A derivative has since been found, œstradiol, whose monobenzoate is much more oil-soluble, namely $5.0 \mathrm{mg} / \mathrm{c.c}$. (50,000 International benzoate units); this discovery has greatly enlarged the scope of œestrogenic therapy. International standards have been set up for the assay of preparations consisting of, or purporting to contain œstrone or œstradiol benzoate (the two œstrogenic substances most commonly used by clinicians), the official units being the œstrogenic activity of $\frac{1}{10000} \mathrm{mg}$. of the appropriate crystalline standard preparation. If $\mathrm{I} . \mathrm{O} \mathrm{mg}$. of œstrone or of œstradiol benzoate is prescribed, this will be equivalent to Io,000 International units, or International benzoate units, as the case may be.

Estrin when administered by mouth has only about one fifth of the effect when given intramuscularly in the same dose. When administering œstrin, it should be remembered that the secretion of this substance never falls to zero, and that even at the end of the menstrual cycle, when the corpus luteum is active, œstrin is still being secreted into the blood stream. For this reason, it is customary to give large doses of œstrin only during the first half of the menstrual cycle, i.e. before ovulation occurs.

The hormone produced by the corpus luteum is variously described by the manufacturers, as progestin, proluton, progesterone, etc. The preparation is expensive because of the difficulties in obtaining large quantities. Reliable preparations are now standardized according to weight or International units. One milligramme of progestin is equivalent to I International unit. The hormone can be obtained in doses of I to $5 \mathrm{mgms}$. per I c.c. This hormone should be administered by intramuscular injection exclusively.

The anterior lobe preparation which has a gonad stimulating effect is called Prolan, and there are various proprietary names for such a preparation, i.e. Pregnyl, Antuitrin S, etc. This substance is only allied to the true hormone which is secreted by the anterior lobe of the pituitary, and for this reason it is often termed the anterior pituitary-like substance. It is impossible, at present to obtain, for general use, the pure preparation from the pituitary body itself, which is more powerful than the present preparation. It is possible that better results will be obtained in the future by the use of the hormone obtained from the serum of pregnant animals.

The anterior pituitary-like gonadotropic hormone is described in rat units, and preparations of this substance can be obtained containing roo rat units per I c.c. This substance degenerates rapidly and should always be used in a fresh condition, and it should be stored in cold surroundings.

All these hormones are best administered by hypodermic injection, as all of them, except œstrin, are valueless when given by mouth.

There are many gynæcological conditions in which it is justifiable, and useful, to administer hormone therapy, but it is essential to have a thorough knowledge of the physiology of the subject before such treatment is ordered. In some types of irregularity of menstruation, and irregular bleeding, it is possible for almost the same symptoms to be produced by an excessive production of 
either of two different hormones, although the pathological changes in the endometrium will be different. In such cases, it is absolutely necessary to understand the true pathology of the condition, if hormones are to be administered.

\section{Menopausal Symptoms.}

At the time of the menopause, the blood content curve of gonadotropic hormone rises, and the estrin curve falls. The rationale of treatment in such a condition, is to administer ostrin over a fairly long period of time so that the body may gradually become accustomed to the deficiency of œstrin.

Estrin therapy gives a feeling of well-being at the time of the menopause, and the most distressing symptoms are often alleviated. The chief symptoms which can be treated in this way are, hot flushes, tachycardia, indigestion and nervousness. In many cases also, the sweatings, vertigo, depression, and change of character which are so characteristic at the menopause will respond well to the same treatment.

In women of menopausal age, the dose of œstrin may be varied according to the severity of the symptoms. In the mild cases, I,000 International units by mouth, daily may be sufficient. This should be continued for three weeks, and afterwards I,000 International units are given twice a week for two months.

In more severe cases, at the time of the menopause, 50,000 International units are given by injection, twice a week for two weeks, followed by 10,000 International units twice a week for four weeks, followed by oral administration of $I, 000$ International units daily for two months.

In young women who have had the ovaries removed by operation, or their function destroyed by irradiation, much larger doses are recommended, 500,000 International units twice weekly for two weeks, followed by 100,000 International units weekly for six weeks. The dose is then gradually reduced over a period of four to six weeks.

Some cases of idiopathic pruritus, either local or general, when occurring at the time of the menopause respond well to large doses of œstrin given by injection. There is sometimes a temporary exacerbation of the irritation for a day or two after the treatment commences. Some cases of kraurosis vulvæ also respond to large doses of œstrin, and the accompanying irritation disappears.

It is, of course, absolutely wrong to treat any case of irregular hæmorrhage, at the menopause, by hormone therapy, without first making certain of the diagnosis by curettage and by other methods.

\section{Menorrhagia.}

The troublesome menorrhagia of puberty may be treated rather successfully by administration of corpus luteum hormone. Progestin is given in I to 2 milligramme doses, four days before, and one day before the period is due. After three months, some anterior lobe preparation such as Pregnyl, or Antuitrin S should be administered in doses of Ioo rat units three times in the ten days before a period is due, and 30 rat units daily during the period.

Menorrhagia, before and at the time of the menopause, is so often due to some mechanical disability in the uterus that it is seldom justifiable to treat such cases by hormone therapy alone. 


\section{Epimenorrhøea.}

Some cases of epimenorrhœa are troublesome in that a patient, who has previously menstruated regularly every month, begins to have a reduced cycle of two or three weeks. In such cases it is worth while trying the effect of injections of ro,00o International units of ostrin on alternate days for the first fourteen days of the cycle, followed by the same injection twice a week during the next fourteen days.

It seems that administration of œstrin throughout a menstrual cycle will delay the onset of menstruation. This is either because the ostrin is antagonistic to the development of the corpus luteum, or because œstrin inhibits the activity of the anterior lobe hormone.

\section{Irregular Bleeding.}

This is a very complex subject, but it must be taken, as a general rule, that irregular bleeding at the menopausal age, and before and after this age, should not be assumed to be endocrine in origin, unless malignant disease has been proved to be absent.

In young women, there is sometimes a typical history of metropathia hæmorrhagica, in which a short period of amenorrhœa is followed by continuous or irregular bleeding for many weeks. The physical signs may be those of a slightly enlarged uterus and a small follicular cyst in one ovary.

Such cases respond well to treatment with corpus luteum hormone. From 3 to $5 \mathrm{mgms}$. of Progestin are administered daily for four days, during the continuous bleeding. If this is not successful, it may be necessary to wait one week, and then give ro-20 mgms. of Progestin spread over 5 to 6 days. (Kaufmann.)

\section{Oligomenorrhœe.}

Young women who have scanty menstruation, often have a hypoplasia of the genital organs. There is also, sometimes, an associated lack of development of the secondary sex characteristics. Such cases are associated with infertility and long periods of amenorrhoea of a secondary type. This syndrome may be due primarily to an anterior pituitary deficiency, or to a deficient ovarian secretion alone. Myxœdema is often associated with the pituitary type, and such patients respond well to administration of thyroid, which may be coupled with injections of the anterior lobe hormone in doses of roo rat units, three times a week, for six weeks at a time.

\section{Amenorrhœa.}

Primary amenorrhœa, which is not due to a physiological delay of puberty, is probably an anterior lobe deficiency problem. In such cases, the uterus is nearly always very poorly developed. Kaufmann has shown that it is quite possible to make such women menstruate by enormous injections of ostrin followed by Progestin. This is simply a substitution therapy and as soon as the injections cease, amenorrhœea begins again. The ovaries which are immature in type are not stimulated to function by the artificial addition of ostrin and Progestin to the patient's blood stream. 
Secondary amenorrhœe is a common condition, and some types respond to hormone therapy quite well. The hypothyroid type has already been mentioned, and responds to thyroid medication. Another type may be treated with a course of injections of ostrin, which are spaced as follows :-50,000 International units every fourth day for 20 days, six in all. For the next ten days 4,000 International units by mouth daily. This cycle is then repeated for three or four months.

There is some evidence for saying that ultra-violet irradiation is useful in stimulating ovarian function.

There are so many indirect causes of secondary amenhorrhœea that it is important to investigate such cases very carefully, before hormone therapy is advised, otherwise many patients will be treated unnecessarily by an expensive and unjustifiable method.

\section{Dysmenorrhœe.}

The treatment of primary dysmenorrhœea by hormones is unsatisfactory, although theoretically the condition should respond well to injection of corpus luteum hormone. Although success has been claimed by some, with this method of treatment, the author has had no successful results at all. It is possible to obtain dramatic temporary cures in some cases of intrinsic dysmenorrhœa by injection of inert solutions.

Thyroid in small doses may be tried in some cases, provided that the patiento is closely watched throughout the treatment.

In dysmenorrhœa, associated with scanty menstruation, it is justifiable to try the effect of injections with œstrin 50,000 International units five times in the first I7 days of each menstrual cycle. The effect of these injections should be to increase the size of the uterus, and the growth of the endometrium during the first half of the cycle, which will lead to an increased menstrual flow.

\section{Sterility.}

This condition is a very complex one, and requires the most careful investigation before any hormone treatment is advised. It is impossible, within the scope of this article, to discuss ovarian and pituitary endocrinology in relation to sterility. Such cases should not be treated by administration of ovarian or pituitary hormones unless there is a definite indication for such prescription. Thyroid extract is useful in a certain type of case in which there is evidence of thyroid deficiency.

\section{OBSTETRICAL CONDITIONS.}

\section{Threatened Abortion.}

After excluding such causes as fibroids, nephritis, retroversion, etc., cases of recurrent abortion may be treated by injections of corpus luteum, or anterior lobe hormone, with good prospects of success.

In conjunction with this hormone treatment, it is still absolutely necessary to treat the patient on general lines as well, such as rest at the time when the period is due, and when the uterus is most irritable, and at the time when the abortion took place before. No intercourse should be allowed, and no drastic 
purgatives should be given. Thyroid is useful for the patient who is of the hypothyroid type. Calcium, and Vitamin E, in the form of wheat germ oil, should also be prescribed.

The best hormone treatment is the use of Progestin, 2 mgms. twice a week as soon as pregnancy begins. Twenty-four hours before a period would have come on, were pregnancy not present, 5 mgms. of Progestin should be given. If bleeding commences, 5 mgms. of Progestin are injected every day for five days, even if the hæmorrhage has ceased.

It is possible to modify this treatment, and give smaller doses with fair hope of success, and after the dangerous time has passed, the anterior lobe hormone may be substituted in doses of Ioo rat units twice a week.

It is often unnecessary to give Progestin after the first few months of pregnancy have passed, but in cases in which the abortion has previously occurred late, the injections must be continued until after this time has passed. They should never be given after the eighth month for fear of delaying the onset of labour at full term.

\section{Missed Abortion and Premature Death of Fœtus.}

It is quite impossible to produce abortion or the onset of premature labour by injection of œestrin, when the fotus is still alive. In cases of missed abortion, and when the fœetus dies in utero, after the 28th week, it is sometimes possible to make the uterus empty itself by stimulating the myometrium with œstrin and pituitrin. If this can be brought about, the complications of hæmorrhage and sepsis, which may follow operative interference, are avoided.

In missed abortion, huge doses of œstrin are recommended, i.e., 40,000 Int. benzoate units every 8 hours. On the fifth day quinine and pituitrin are administered, and the œstrin is continued up to the 8th or 9th day if labour does not commence. In Jeaffcote's series, success was obtained in 7 out of 9 cases before the 28th week, but it is stressed that an average of 2,000,000 units were given over a period of I40 hours. It is possible to obtain the desired result with smaller doses in some cases.

After the 28th week of pregnancy, the uterus is more easily stimulated, and will respond to smaller doses of œstrin.

\section{Afterpains.}

The pain caused by irregular contractions of the uterus in the first few days of the puerperium, may be very troublesome in a multipara.

In a primigravida, the retraction and contraction of the uterus during the puerperium goes on rhythmically, but in the multipara the contractions are spasmodic, and, therefore, painful. In such cases it is justifiable to administer Progestin in doses of 2 mgms. a few hours after delivery, and again the next day, if necessary.

\section{Inhibition of Lactation.}

It is now generally recognized that œstrin is responsible for the hypertrophy of the breasts during pregnancy. It is possible that, while the placenta is still 
attached to the uterus, the œstrin, which is stored in huge quantities within it, is capable of inhibiting the secretion of prolactin from the pituitary body. In this way, lactation does not occur until some time after the placenta has separated, and a large quantity of œestrin has been removed with it.

It is possible to inhibit lactation by injections of ostrin given on the first three or four days after the baby is born. This method is particularly useful in cases of still birth, and when there has been a difficult delivery with bruising of the anterior vaginal wall, cystitis, post-partum hæmorrhage, or obstetrical shock, etc. In such cases it is against the interests of the patient to cut down fluids to prevent excessive engorgement of the breasts on about the third day. In other cases, if there has been a tear of the perineum it is unwise to give large doses of salts, in conjunction with a reduction of fluids, for if the bowels are opened frequently during the first few days of the puerperium, the perineal wound will tend to break down. All these complications, when associated with stillbirth, can be best treated by inhibiting lactation with ostrin, and the treatment of the complication can then proceed without hinderance.

If œestrin is given, in sufficient doses, the patient will suffer no discomfort from the breasts, even at the third and fourth days, and fluids may be given in excess at the same time.

The author has had complete success in inhibiting the onset of lactation with injections of œstrin, 50,000 Int. benzoate units on the first, second and third days of the puerperium. It is unnecessary to bind the breasts, reduce fluids, or give saline purges.

Snœck has equal success using much smaller doses of œstrin. It is probable, ? therefore, that injections of $50,000,36,000$ and 14,000 units on successive days would be sufficient. It is possible to inhibit lactation 24 hours after its commencement by giving the same doses. 